\title{
ELECTRICAL PROPERTIES OF FLY ASH GEOPOLYMER COMPOSITES WITH GRAPHITE CONDUCTIVE ADMIXTURES
}

\author{
Cecílie Mizerová*, Ivo Kusák, Pavel Rovnaník
}

\author{
Brno University of Technology, Faculty of Civil Engineering, Žižkova 17, 60200 Brno, Czech Republic \\ * corresponding author: mizerova.c@fce.vutbr.cz
}

\begin{abstract}
Construction materials with increased electrical conductivity could be possibly used in health monitoring of structures (stress, deformation, damages), their maintenance or traffic monitoring. The aim of this study was the application of functional filler and its influence on the electrical properties of the alkali-activated fly ash matrix. The graphite powder was added to the reference material in the amount of $2-10 \%$. Besides the assessment of the critical amount of filler necessary to achieve a percolation threshold in the structure of the composite, the effect on the electrical properties of the matrix (resistance, capacitance, conductivity) was determined. The optimal amount of filler was also determined with respect to the changes in microstructure of the binder and its mechanical properties.
\end{abstract}

KEYWORDS: Fly ash, geopolymer, graphite, electrical properties, mechanical properties, microstructure.

\section{INTRODUCTION}

Recently, one of the field in materials and structures research is the concept of advanced smart (or selfsensing) material. Its composition design is based on the content of conductive fillers that enhance its electrical properties. For example, smart composite with higher electrical conductivity can be used for the assessment of structural health in terms of stress monitoring, localization of cracks and damages, humidity and temperature changes etc. [1]. There is a wide range of different functional fillers to use: steel fibres, carbon black, graphite powder, carbon fibres (CF), carbon nanotubes (CNF), graphene, nickel powder.

So far, this approach has been studied predominantly in traditional cement concretes and composites technology. Alkali-activated materials are binders derived from the reactions of raw materials with a high content of amorphous aluminosilicate phase with alkaline activator solution. Alkaline activator (most often in form of alkali hydroxides and/or alkali silicates) is required for the appropriate conditions for the dissolution rate and the formation of new phases [2]. The first theoretical background of alkaline activation was developed by Glukhovsky in 1959 [3. The term "geopolymer" was firstly used by prof. Davidovits and refers to a material formed by almost exclusively highly coordinated units of aluminosilicate structures forming regular polymeric three-dimensional structure [4].

Compared to clay-based geopolymers, fly ash provides more favourable rheology of the fresh binder [5], strength of the hardened binder can be enhanced by thermal treatment. Properties of alkali-activated binders are comparable or superior to Portland cement binders 6]. Fly ash geopolymers are generally more durable because of higher chemical and thermal resistance [7]. Moreover, the geopolymer production using mostly secondary raw materials do not require an exploitation of natural resources and high energy consumption that significantly contribute to lower emissions of $\mathrm{CO}_{2}$ compared to Portland cement [8].

According to Hanjitsuvan et al. [9, 10, the electrical conductivity of fly ash geopolymer matrix is affected by the $\mathrm{NaOH}$ concentration in activator solution, the frequency spectrum and liquid activator/ash ratio (L/A). Payakaniti [11] studied properties of geopolymer incorporated with $\mathrm{CF}$ stating the percolation threshold was reached by the geopolymer with $0.5 \%$ $\mathrm{CF}$ content, this value was increasing with growing L/A. This CF content was also responsible for the best mechanical performance. Vaidya et al. [12] tested fly ash geopolymer concrete beams and cylinders with $0.4 \%$ CF while exposed to bending and compressive stress to assess the changes of electrical resistance. Regarding the application of CNT in geopolymer concrete, Saafi et al. 13] states that the optimal dosage is $0.5 \%$ which ensures the improvement of both electrical and mechanical performance, higher percentage leads to less effective dispersion and thus cluster formation within the matrix. In another study, the author used graphene as a conductive filler [14]. Only $0.35 \%$ addition of graphene resulted in significant increase of strength and modulus of elasticity accompanied by lower porosity and $209 \%$ increase of conductivity.

This paper is focused on the application of graphite powder as a conductive admixture in fly ash geopolymer mortars considering its impact on selected electrical properties, strength and changes in binder microstructure.

\section{Materials And Methods}

The geopolymer binder was produced by mixing of fly ash (FA) with commercial sodium silicate solution with $\mathrm{SiO}_{2} / \mathrm{Na}_{2} \mathrm{O}=1.6$. The fly ash is a product of black coal combustion and its chemical composition is given in Table 1. Quartz sand with a maximum 


\begin{tabular}{ccccccccc}
\hline & $\mathrm{SiO}_{2}$ & $\mathrm{Al}_{2} \mathrm{O}_{3}$ & $\mathrm{Fe}_{2} \mathrm{O}_{3}$ & $\mathrm{CaO}$ & $\mathrm{MgO}$ & $\mathrm{S}_{\text {total }}$ & $\mathrm{Na}_{2} \mathrm{O}$ & $\mathrm{K}_{2} \mathrm{O}$ \\
\hline$(\%)$ & 49.82 & 24.67 & 7.5 & 3.91 & 2.68 & 0.91 & 0.7 & 2.78 \\
\hline
\end{tabular}

TABLE 1. Chemical composition of fly ash.

\begin{tabular}{cccccccc}
\hline & REF & G2 & G4 & G5 & G6 & G8 & G10 \\
\hline Fly ash (g) & 350 & 350 & 350 & 350 & 350 & 350 & 350 \\
Sodium silicate (g) & 280 & 280 & 280 & 280 & 280 & 280 & 280 \\
Graphite powder (g) & - & 7 & 14 & 17.5 & 21 & 28 & 35 \\
Sand (g) & 1050 & 1050 & 1050 & 1050 & 1050 & 1050 & 1050 \\
$2 \%$ Triton X-100 (g) & - & 7 & 14 & 17.5 & 21 & 28 & 35 \\
$1 \%$ Lukosan (g) & - & 3 & 6 & 7.5 & 7.5 & 7.5 & 7.5 \\
Water (g) & 35 & 30 & 30 & 32 & 32 & 32 & 32 \\
\hline
\end{tabular}

TABLE 2. Mix composition of FA geopolymer mortars with graphite powder.

grain size of $2.5 \mathrm{~mm}$ was used as aggregate. Graphite powder PMM 11 was used as a conductive filler in 2, $4,5,6,8$ and $10 \%$ wt. of the fly ash and its dispersion within the matrix was supported by the addition of dispersing agent $(2 \%$ Triton X-100). Defoaming agent (1\% Lukosan) was introduced to reduce the air content in fresh and hardened binder.

The raw mix composition is presented in Table 2 Each of the mixes was produced following these steps: at first, the fly ash was mixed with water glass. Then, the graphite powder and dispersing agent were added and homogenized with the binder and a small amount of water, if needed. Thereafter, each fraction of aggregate (from fine to coarse) was added and mixed properly. The defoaming agent and remaining amout of water were added at the very end of the mixing procedure.

The mortars were cast into prismatic moulds $(40 \times$ $40 \times 160 \mathrm{~mm}$ ) and covered with a plastic sealant to avoid moisture loss. After 2 hours in the ambient conditions, the specimens were heated at $40^{\circ} \mathrm{C}$ for $24 \mathrm{~h}$. After demoulding, the hardened specimens were stored in the laboratory conditions $\left(22 \pm 2{ }^{\circ} \mathrm{C}, \varphi=45 \pm 5 \%\right)$ till the age of testing.

The electrical and mechanical properties (compressive and flexural strength) were tested at the age of 56 days. The prepared prismatic samples were characterized by impedance spectroscopy in the range of $40 \mathrm{~Hz}$ to $1 \mathrm{MHz}$ using an Agilent 33220A sinusoidal signal generator and an Agilent 54645A dual-channel oscilloscope. The output voltage of the signal generator was $5.5 \mathrm{~V}$. The input values for the electrical capacity and the resistance of the oscilloscope were $13 \mathrm{pF}$ and $1 \mathrm{M} \Omega$, respectively. In order to perform impedance analysis, the prismatic specimens were placed between parallel brass electrodes $(30 \times 100 \mathrm{~mm})$ so that a distance between electrodes was $40 \mathrm{~mm}$. Conductivity measurements were performed in the range of 10 to $3510 \mathrm{MHz}$. The microstructure and porosity of the geopolymers were evaluated using Micromeritics Pore- sizer 9310 and scanning electron microscope (SEM) Tescan MIRA3 XMU.

\section{Results AND Discussion}

Electrical resistance of all samples decreased with higher frequency applied, as can be seen from Fig. 1 The lowest resistance was observed in case of $10 \%$ graphite content (G10), at all frequencies. The differences in resistance curves are clearly visible up to $10 \mathrm{kHz}$. Above this frequency, the resistance of all samples fluctuate and the curves overlap. At $100 \mathrm{~Hz}$, the resistance of reference sample was $159.80 \mathrm{M} \Omega$. The resistance of G5 dropped to $43.78 \mathrm{M} \Omega$ and $0.85 \mathrm{M} \Omega$ only at G10.

Changes of resistance and conductivity at chosen frequency are shown in Fig. 2. While the resistance decreased continuously, we registered an exceptional increase in conductivity of specimen G10 from 0.38 to $6.31 \mathrm{mS} \cdot \mathrm{m}^{-1}$. These results suggest that geopolymer with $10 \%$ of graphite may have reached the percolation threshold.

The capacitance of geopolymers with various graphite content as a function of frequency is shown in Fig. 3 Up to $6 \%$ of graphite, the changes in capacitance are comparable, but the capacitance of G8 and G10 shows the most notable increase over all frequencies. Capacitance of all samples except G10 decreased with higher frequency. The capacitance of G10 first dropped from 222 to $122 \mathrm{pF}(40-180 \mathrm{~Hz})$, within the frequency $180-10000 \mathrm{~Hz}$ it was about $125 \mathrm{pF}$ and at higher frequency applied it was decreasing again.

The changes of mechanical performance depending on the graphite content are displayed in Fig. 4 The flexural strength was not negatively influenced by the graphite addition and fluctuated around $5 \mathrm{MPa}$ at all graphite concentrations. On the contrary, the compressive strength gradually decreased. While the reference sample without graphite reached $23.5 \mathrm{MPa}$, the samples with $2 \%$ graphite content (G2) reached $17.7 \mathrm{MPa}$ and $10 \%$ graphite content (G10) 


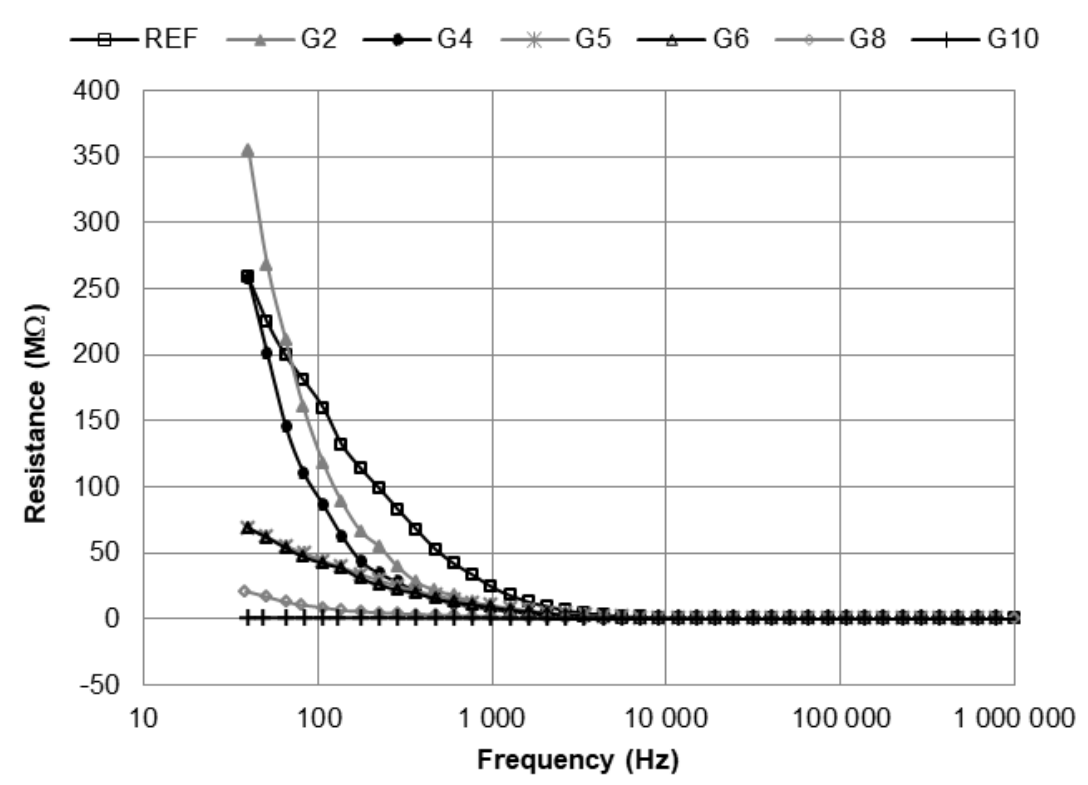

FIGURE 1. Variation in electrical resistance of FA geopolymers with different graphite content.

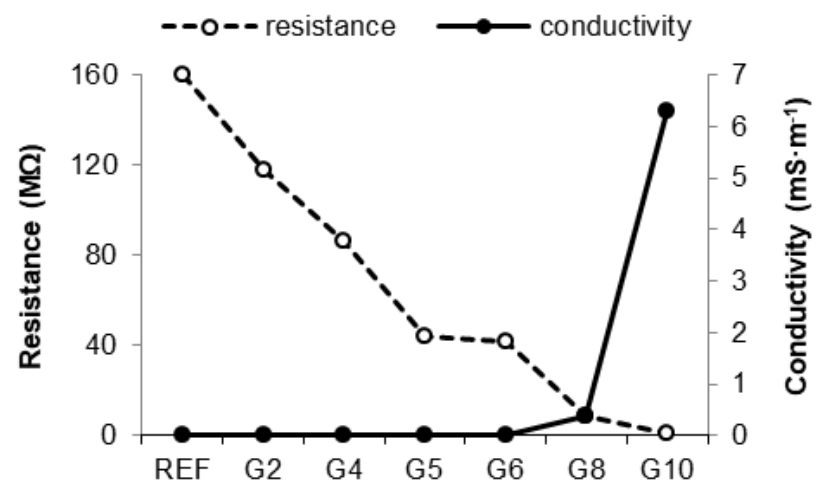

Figure 2. Resistance (at $100 \mathrm{~Hz}$ ) and conductivity (at $100 \mathrm{MHz}$ ) of FA geopolymers with different graphite content.

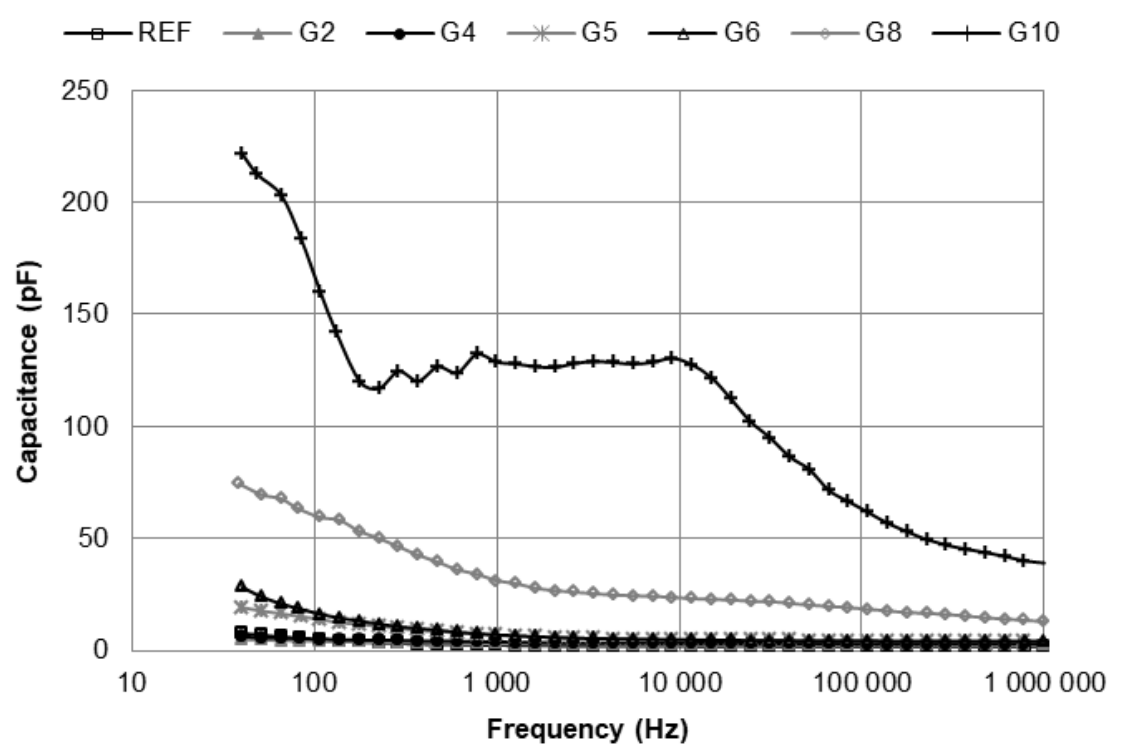

FiguRE 3. Variation in capacitance of FA geopolymers with different graphite content. 


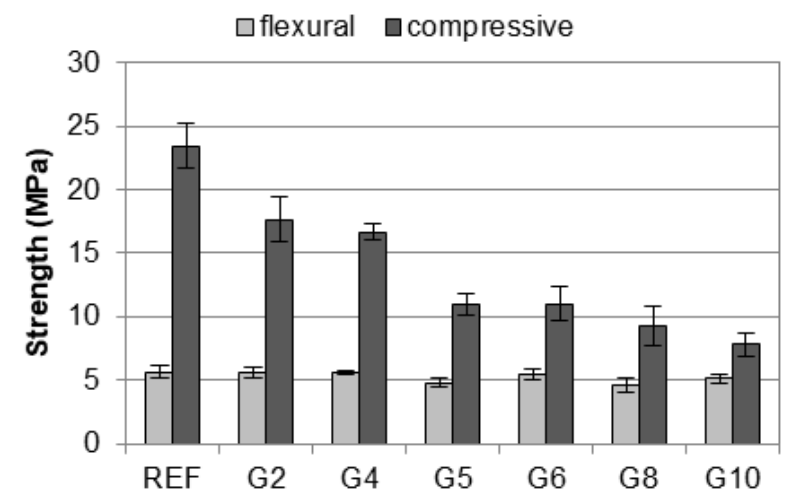

FiguRE 4. Mechanical properties of FA geopolymers with different graphite content.

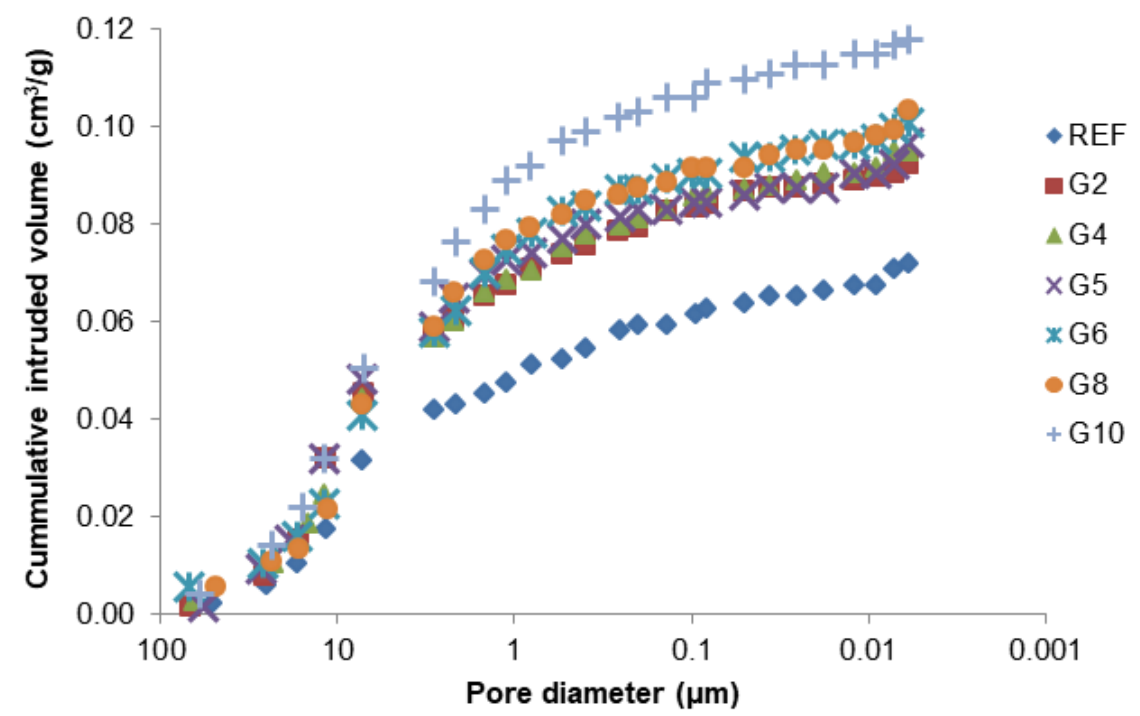

Figure 5. Cumulative intruded volume of FA geopolymers with different graphite content.

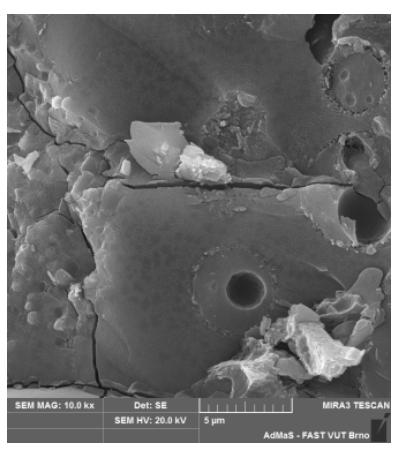

(A) . REF.

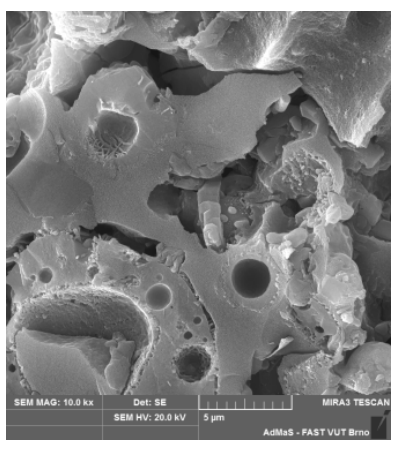

(B) . G2.

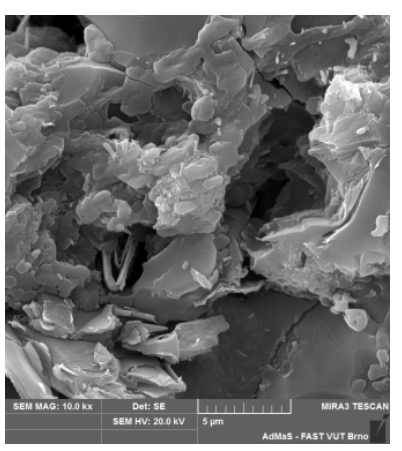

(c) . G5.

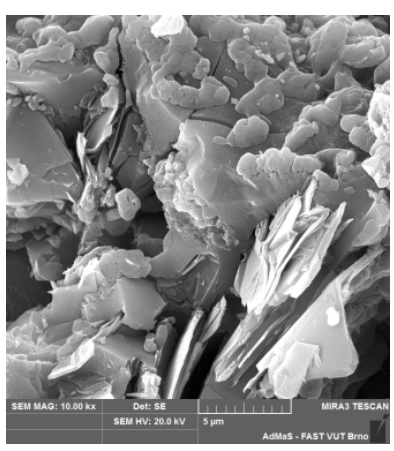

(D) . G10.

Figure 6. SEM images of REF, G2, G5 and G10 geopolymers. 
only $7.8 \mathrm{MPa}$, which is equal to $25 \%$ and $65 \%$ drop of strength, respectively.

Regarding the microstructure of the geopolymer binder, even $2 \%$ of graphite caused an increase in total porosity of the samples (Fig. 5). While the geopolymers with a graphite content of $2-8 \%$ did not exhibit considerable differences, we observed a further increase in pore volume of G10 which is more than $60 \%$ higher than the reference sample.

In Fig. 6] we can see the nature of chosen binders in SEM images. Reference sample is characterized by homogeneous amorphous binder phase whereas number of pores and inhomogeneities increased with the amount of conductive filler.

\section{Conclusions}

The results mentioned above confirm that graphite powder can be applied to fly ash geopolymer matrix to enhance its electrical properties. Higher graphite content resulted in reduced electrical resistance, especially in frequency up to $1000 \mathrm{~Hz}$. Likewise, the samples with high graphite content exhibited an increase in capacitance. The best performance in terms of electrical properties was observed in case of geopolymer with $10 \%$ graphite content providing significant increase in conductivity, which may refer to achieving the percolation threshold. However, the presence of conductive filler in such concentration deteriorated the mechanical performance in compression by more than $65 \%$; flexural strength of all samples remained constant regardless of the amount of graphite powder. Despite the use of the defoaming agent, the microstructure of all geopolymers with graphite was characterized by higher pore volume which is in a good accordance with reduced compressive strength. We can conclude that graphite powder in fly ash geopolymer allows to develop a conductive network within the matrix but also causes generation of additional pores during mixing. The negative impact of graphite powder on the compressive strength is apparently attributed to a weak bond between the matrix and graphite particles because of nonpolar character of graphite surface. Low toughness of graphite itself can further contribute to the strength loss at high concentrations. Possible ways to reduce these impacts include more efficient defoaming or improved adhesion of graphite particles to the matrix by partial modification of its structure with hydrophilic substituents.

\section{ACKNOWLEDGEMENTS}

This study has been financially supported by the BUT specific research project FAST-J-18-5484 and by Ministry of Education, Youth and Sports under the 'National Sustainability Programme I' - the project No. LO1408 AdMaS UP.

\section{REFERENCES}

[1] B. Han, L. Zhang, J. Ou. Smart and Multifunctional Concrete Toward Sustainable Infrastructures, chap. Self-Sensing Concrete, pp. 81-116. Springer, Singapore, 2017. DOI:10.1007/978-981-10-4349-9_6

[2] C. Shi, D. Roy, P. Krivenko. Alkali-Activated Cements and Concretes. CRC press, 2003. DOI:10.1201/9781482266900

[3] V. D. Glukhovsky. Soil silicates (Gruntosilikaty). Budivelnik Publisher, Kiev, 1959.

[4] J. Davidovits. Properties of geopolymer cements. In First international conference on alkaline cements and concretes, pp. 131-149. 1994.

[5] L. Provis, J. S. van Deventer. Alkali Activated Materials. Springer, 2014. DOI:10.1007/978-94-007-7672-2.

[6] P. Duxson, A. Fernández-Jiménez, J. L. Provis, et al. Geopolymer technology: the current state of the art. Journal of materials science 42(9):2917-2933, 2007. DOI:10.1007/s10853-006-0637-z.

[7] A. Fernández-Jiménez, I. García-Lodeiro, A. Palomo. Durability of alkali-activated fly ash cementitious materials. Journal of Materials Science 42(09):30553065, 2007. DOI:10.1007/s10853-006-0584-8

[8] K. P. Mehta. Reducing the environmental impact of concrete. Concrete international 23(10):61-66, 2001.

[9] S. Hanjitsuwan, S. Hunpratub, P. Thongbai, et al. Effects of $\mathrm{NaOH}$ concentrations on physical and electrical properties of high calcium fly ash geopolymer paste. Cement and Concrete Composites 45:9-14, 2014. DOI:10.1016/j.cemconcomp.2013.09.012

[10] S. Hanjitsuwan, P. Chindaprasirt, K. Pimraksa. Electrical conductivity and dielectric property of fly ash geopolymer pastes. International Journal of Minerals, Metallurgy, and Materials 18(1):94-99, 2011. DOI:10.1007/s12613-011-0406-0

[11] P. Payakaniti, S. Pinitsoontorn, P. Thongbai, et al. Electrical conductivity and compressive strength of carbon fiber reinforced fly ash geopolymeric composites. Construction and Building Materials 135:164-176, 2017. DOI:10.1016/j.conbuildmat.2016.12.198.

[12] S. Vaidya, E. N. Allouche. Strain sensing of carbon fiber reinforced geopolymer concrete. Materials and structures 44(8):1467-1475, 2011. DOI:10.1617/s11527-011-9711-3

[13] M. Saafi, K. Andrew, P. L. Tang, et al. Multifunctional properties of carbon nanotube/fly ash geopolymeric nanocomposites. Construction and Building Materials 49:46-55, 2013. DOI:10.1016/j.conbuildmat.2013.08.007.

[14] M. Saafi, L. Tang, J. Fung, et al. Graphene/fly ash geopolymeric composites as self-sensing structural materials. Smart materials and structures 23(6):065006, 2014. DOI:10.1088/0964-1726/23/6/065006 